\title{
Biomass Conversion Technologies for Renewable Energy and Fuels: A Review Note.
}

\author{
Sumit Sharma ${ }^{1}$, Rajendra Meena ${ }^{2}$, Amit Sharma $^{3}$, Pawan kumar Goyal ${ }^{4}$ \\ ${ }^{I}$ (Asst. Prof., Dept. of Mechanical Engg, Vivekanand Inst. of Technology, Jaipur, Raj., India) \\ ${ }^{2}$ (Asst. Prof., Dept. of Mechanical Engg, PCE, Jaipur, Raj., India) \\ ${ }^{3}$ (Asst. Prof., Dept. of Mechanical Engg, AIT, Ajmer, Raj., India) \\ ${ }_{4}^{4}$ (Asst.Prof., Dept. of Mechanical Engg, VIT, Jaipur, Raj., India)
}

\begin{abstract}
The world's energy markets rely heavily on the fossil fuels coal, petroleum crude oil, and natural gas as sources of thermal energy; gaseous, liquid, and solid fuels; and chemicals. Since millions of years are required to form fossil fuels in the earth, their reserves are finite and subject to depletion as they are consumed. The only natural, renewable carbon resource known that is large enough to be used as a substitute for fossil fuels is biomass. This article gives an overview of the state-of-the-art of key biomass conversion technologies currently deployed and technologies that may play a key role in the future, including possible linkage to $\mathrm{CO}_{2}$ capture and sequestration technology (CCS). In doing so, special attention is paid to production of biofuels for the transport sector, because this is likely to become the key emerging market for large-scale sustainable biomass use. A range from 200 to 300 EJ may be observed looking well into this century, making biomass a more important energy supply option than mineral oil today. A key issue for bio-energy is that its use should be modernized to fit into a sustainable development path. Especially promising are the production of electricity via advanced conversion concepts (i.e. gasification and state-of-the-art combustion and co-firing) and modern biomass derived fuels like methanol, hydrogen and ethanol from ligno-cellulosic biomass, which can reach competitive cost levels within 1-2 decades (partly depending on price developments with petroleum). The gasification route offers special possibilities to combine this with low cost $\mathrm{CO}_{2}$ capture (and storage), resulting in concepts that are both flexible with respect to primary fuel input as well as product mix and with the possibility of achieving zero or even negative carbon emissions. Further biomass market development, consistent policy support, $R D \& D$ efforts and international collaboration are essential to achieve this.
\end{abstract}

Keywords : Biomass, Biofuel, Gasification, Ethanol etc.

\section{INTRODUCTION}

There are five fundamental forms of biomass energy use are.

(1) The "traditional domestic" use in developing countries (fuelwood, charcoal and agricultural residues) for household cooking (e.g. the "three stone fire"), lighting and space-heating. In this role-the efficiency of conversion of the biomass to useful energy generally lies between $5 \%$ to $15 \%$.

(2) The "traditional industrial" use of biomass for the processing of tobacco, tea, pig iron, bricks \& tiles, etc, where the biomass feedstock is often regarded as a "free" energy source. There is generally little incentive to use the biomass efficiently so conversion of the feedstock to useful energy commonly occurs at an efficiency of $15 \%$ or less.

(3) "Modern industrial." Industries are experimenting with technologically advanced thermal conversion technologies. Expected conversion efficiencies are between 30 and 55\%.

(4) Newer "chemical conversion" technologies ("fuel cell") which are capable of by-passing the entropy-dictated Carnot limit which describes the maximum theoretical conversion efficiencies of thermal units.

(5) "Biological conversion" techniques, including anaerobic digestion for biogas production \& fermentation for alcohol [1].

The capture of solar energy as fixed carbon in biomass via photosynthesis, during which carbon dioxide $\left(\mathrm{CO}_{2}\right)$ is converted to organic compounds, is the key initial step in the growth of virgin biomass and is depicted by the following equation:

$\mathrm{CO}_{2}+\mathrm{H}_{2} \mathrm{O}+$ light + chlorophyll $\rightarrow\left(\mathrm{CH}_{2} \mathrm{O}\right)+\mathrm{O}_{2}$

Carbohydrate, represented by the building block $\left(\mathrm{CH}_{2} \mathrm{O}\right)$, is the primary organic product. For each gram mole of carbon fixed, about $470 \mathrm{~kJ}(112 \mathrm{kcal})$ is absorbed. The upper limit of the capture efficiency of the incident solar radiation in biomass has been estimated to range from about $8 \%$ to as high as $15 \%$, but under most conditions in the field, it is generally less than $2 \%$ [2]. The global energy potential of virgin biomass is very large. It is estimated that the world's standing terrestrial biomass carbon (i.e., the renewable, above-ground biomass that could be harvested and used as an energy resource) is approximately 100 times the world's total annual energy consumption. The largest source of standing terrestrial biomass carbon is forest biomass, which contains about 
80 to $90 \%$ of the total biomass carbon. Interestingly, marine biomass carbon is projected to be next after the forest biomass carbon in terms of net annual production, but is last in terms of availability because of its high turnover rates in an oceanic environment. The main features of how biomass is used as a source of energy and fuels are schematically illustrated in Fig. 1. Conventionally, biomass is harvested for feed, food, fiber, and materials of construction or is left in the growth areas where natural decomposition occurs. The decomposing biomass or the waste products from the harvesting and processing of biomass, if disposed on or in land, can in theory be partially recovered after a long period of time as fossil fuels. This is indicated by the dashed lines in the figure. The energy content of biomass could be diverted instead to direct heating applications by collection and combustion. Alternatively, biomass and any wastes that result from its processing or consumption could be converted directly into synthetic organic fuels if suitable conversion processes were available. Another route to energy products is to grow certain species of biomass such as the rubber tree (Hevea braziliensis), in which high-energy hydrocarbons are formed within the species by natural biochemical mechanisms, or the Chinese tallow tree (Sapium sebiferum), which affords high-energy triglycerides in a similar manner. In these cases, biomass serves the dual role ofa carbon-fixing apparatus and a continuous source of high-energy organic products without being consumed in the process. Other biomass species, such as the herbaceous guayule bush (Parthenium argentatum) and the gopher plant (Euphorbia lathyris), produce hydrocarbons too, but must be harvested to recover them. Conceptually, Fig. 1 shows that there are several pathways by which energy products and synthetic fuels can be manufactured [7].

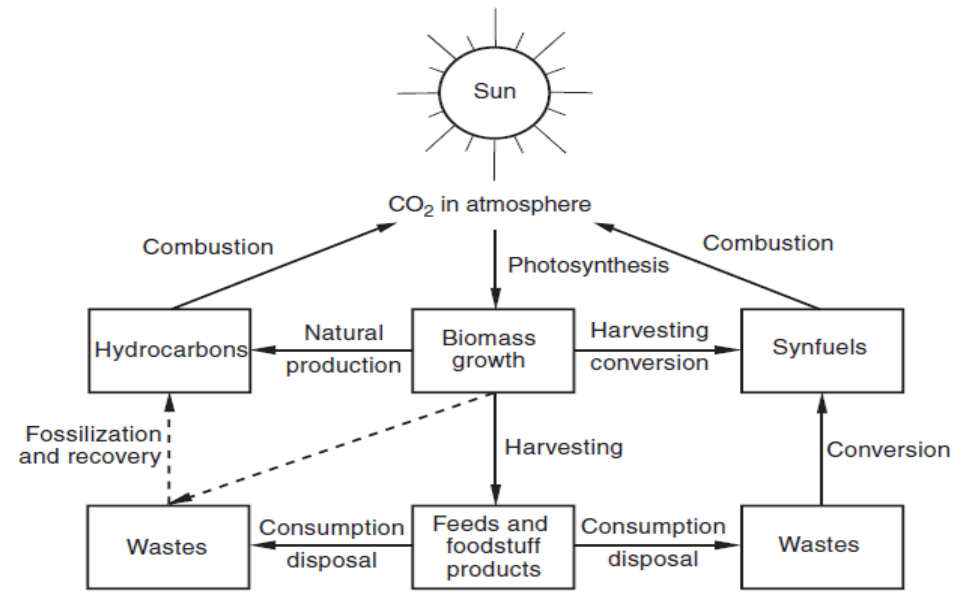

Fig -1: Main features of biomass energy technology From Klass (1998).

\section{Biomass Conversion Technologies}

In general, biomass-to-energy conversion technologies have to deal with a feedstock which can be highly variable in mass and energy density, size, moisture content, and intermittent supply. Therefore, modern industrial technologies are often hybrid fossil-fuel/biomass technologies which use the fossil fuel for drying, preheating and maintaining fuel supply when the biomass supply is interrupted [8].

\subsection{Thermochemical Processes.}

These processes do not necessarily produce useful energy directly, but under controlled temperature and oxygen conditions are used to convert the original biomass feedstock into more convenient forms of energy carriers, such as producer gas, oils or methanol [10]. These carriers are either more energy dense and therefore reduce transport costs, or have more predictable and convenient combustion characteristics allowing them to be used in internal combustion engines and gas turbines and these are:

a) Pyrolysis.

b) Carbonisation.

c) Gasification.

d) Catalytic Liquefaction.

\subsubsection{Pyrolysis}

Pyrolysis is the application of heat to a feedstock in the absence of oxygen to break down the long chain molecules into short chain molecules. Typically the feedstock is biomass or waste, and the process is used to produce a syngas (a mixture of hydrogen, volatile organic compounds, and carbon monoxide). Varying the process conditions allows the production of fluids similar to diesel, and a variety of other products.

A more detailed understanding of the physical and chemical properties governing the pyrolytic reactions has allowed the optimisation of reactor conditions necessary for these types of pyrolysis. Further work is now 
concentrating on the use of high pressure reactor conditions to produce hydrogen and on low pressure catalytic techniques (requiring zeolites) for alcohol production from the pyrolytic oil.

The advantage of pyrolysis and gasification are that they convert solid material into gases and vapours which are less costly to handle, transport and store. The gases will burn in boilers, gas turbines and reciprocating engines increasing fuel flexibility and security. Capturing and combusting the methane and carbon monoxide in syngas makes use of the energy in the gas and produces carbon dioxide which is a less potent greenhouse gas than methane and offsets fossil fuel energy production [12].

The disadvantages of pyrolysis and gasification are that they require heat input to drive the chemical reactions that produce a syngas. Thus some fuel must be used to generate the syngas.

\subsubsection{Carbonisation}

This is an age old pyrolytic process optimised for the production of charcoal. Traditional methods of charcoal production have centred on the use of earth mounds or covered pits into which the wood is piled. Control of the reaction conditions is often crude and relies heavily on experience. The conversion efficiency using these traditional techniques is believed to be very low; on a weight basis estimates that the wood to charcoal conversion rate for such techniques ranges from 6 to 12 tonnes of wood per tonne of charcoal.

During carbonisation most of the volatile components of the wood are eliminated; this process is also called "dry wood distillation." Carbon accumulates mainly due to a reduction in the levels of hydrogen and oxygen in the wood. The wood undergoes a number of physico-chemical changes as the temperature rises. Between 100 and $170^{\circ} \mathrm{C}$ most of the water is evaporated; between $170^{\circ} \mathrm{C}$ and $270^{\circ} \mathrm{C}$ gases develop containing condensible vapours, $\mathrm{CO}$ and $\mathrm{CO}_{2}$. These condensible vapours (long chain carbon molecules) form pyrolysis oil, which can then be used for the production of chemicals or as a fuel after cooling and scrubbing. Between $270^{\circ} \mathrm{C}$ and $280^{\circ} \mathrm{C}$ an exothermic reaction develops which can be detected by the spontaneous generation of heat.

The modernisation of charcoal production has lead to large increases in production efficiencies with large-scale industrial production in Brazil now achieving efficiencies of over 30\% (by weight). There are three basic types of charcoal-making: a) internally heated (by controlled combustion of the raw material), b) externally heated (using fuelwood or fossil fuels), and c) hot circulating gas (retort or converter gas, used for the production of chemicals). Internally heated charcoal kilns are the most common form of charcoal kiln. It is estimated that 10 to $20 \%$ of the wood (by weight) is sacrificed, a further $60 \%$ (by weight) is lost through the conversion to, and release of, gases to the atmosphere from these kilns. Externally heated reactors allow oxygen to be completely excluded, and thus provide better quality charcoal on a larger scale. They do, however, require the use of an external fuel source, which may be provided from the "producer gas" once pyrolysis is initiated.

Recirculating heated gas systems offer the potential to generate large quantities of charcoal and associated byproducts, but are presently limited by high investment costs for large scale plant [11].

\subsubsection{Gasification}

Gasification is the partial oxidation of an organic feedstock to produce a syngas (a mixture of hydrogen, volatile short chain organic compounds, and carbon monoxide). Typically the feedstock is biomass or waste, and varying the process conditions allows control over proportions of the compounds in the syngas. In this approach to the development of fixed carbon supplies from renewable carbon resources is to convert $\mathrm{CO}_{2}$ outside the biomass species to synthetic fuels and organic intermediates. The ambient air, which contains about $360 \mathrm{ppm}$ by volume of $\mathrm{CO}_{2}$, the dissolved $\mathrm{CO}_{2}$ and carbonates in the oceans, and the earth's large carbonate deposits, could serve as renewable carbon resources. But since $\mathrm{CO}_{2}$ is the final oxidation state of fixed carbon, it contains no chemical energy. Energy must be supplied in a chemical reduction step. A convenient method of supplying the required energy and of simultaneously reducing the oxidation state is to reduce $\mathrm{CO}_{2}$ with hydrogen. The end product, for example, can be methane $\left(\mathrm{CH}_{4}\right)$, the dominant component in natural gas and the simplest hydrocarbon known, or other organic compounds. With all components in the ideal gas state, the standard $\mathrm{CO}_{2}+4 \mathrm{H}_{2} \rightarrow \mathrm{CH}_{4}+2 \mathrm{H}_{2} \mathrm{O}$ enthalpy of the process is exothermic by _165 EJ (_39.4 kcal) per gram mole of methane formed [12].

Biomass can also serve as the original source of hydrogen via partial oxidation or steam reforming to yield an intermediate hydrogen-containing product gas. Hydrogen would then effectively act as an energy carrier from the biomass to $\mathrm{CO}_{2}$ to yield a substitute or synthetic natural gas (SNG). The production of other synthetic organic fuels can be carried out in a similar manner. For example, synthesis gas (syngas) is a mixture of hydrogen and carbon oxides. It can be produced by biomass gasification processes for subsequent conversion to a wide range of chemicals and fuels as illustrated in Fig. 2. These include continuous water splitting by electrochemical, biochemical, thermochemical, microbial, photolytic, and biophotolytic processes. The basic concept then of using biomass as a renewable energy resource consists of the capture of solar energy and carbon from ambient $\mathrm{CO}_{2}$ in growing biomass, which is converted to other fuels (biofuels, synfuels, hydrogen) or is used directly as a source of thermal energy or is converted to chemicals or chemical intermediates. For 2000, the 
data compiled by the International Energy Agency (IEA) from a survey of 133 countries indicate that biomass' share of total energy consumption, $430 \mathrm{EJ}$ (408 quad), for these countries is about $10.5 \%$.

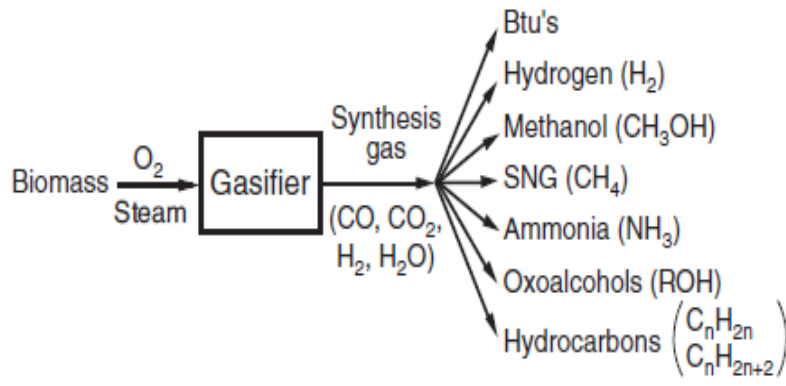

Fig -2: Chemicals from syngas by established processes. From Klass (1998).

High temperatures and a controlled environment leads to virtually all the raw material being converted to gas. This takes place in two stages. In the first stage, the biomass is partially combusted to form producer gas and charcoal. In the second stage, the $\mathrm{C}_{2}$ and $\mathrm{H}_{2} \mathrm{O}$ produced in the first stage is chemically reduced by the charcoal, forming $\mathrm{CO}$ and $\mathrm{H}_{2}$. The composition of the gas is 18 to $20 \% \mathrm{H}_{2}$, an equal portion of $\mathrm{CO}, 2$ to $3 \% \mathrm{CH}_{4}, 8$ to $10 \% \mathrm{CO}_{2}$, and the rest nitrogen. These stages are spatially separated in the gasifier, with gasifier design very much dependant on the feedstock characteristics [14].

Gasification requires temperatures of about $800^{\circ} \mathrm{C}$ and is carried out in closed top or open top gasifiers. These gasifiers can be operated at atmospheric pressure or higher. The energy density of the gas is generally less than $5.6 \mathrm{MJ} / \mathrm{m}^{3}$, which is low in comparison to natural gas at $38 \mathrm{MJ} / \mathrm{m}^{3}$ providing only $60 \%$ the power rating of diesel when used in a modified diesel engine. A major future role is envisaged for electricity production from biomass plantations and agricultural residues using large scale gasifiers with direct coupling to gas turbines. The potential gains in efficiency using such hybrid gasifier/gas turbine systems make them extremely attractive for electricity generation once commercial viability has been demonstrated. Such systems take advantage of low grade and cheap feedstocks (residues and wood produced using short rotation techniques) and the high efficiencies of modern gas turbines to produce electricity at comparable or less cost than fossil-fuel derived electricity. Net atmospheric $\mathrm{CO}_{2}$ emissions are avoided if growth of the biomass is managed to match consumption. The use of BIG/STIG (Biomass Integrated Gasifier Steam Injected Gas turbine) initially and BIG/GTCC (Biomass integrated Gasifier Gas Turbine Combined Cycle) as the technology matures, is predicted to allow energy conversion efficiencies of $40 \%$ to $55 \%$. Modern coal electrical plants have efficiencies of about $35 \%$ or less. Combined Heat and Power systems could eventually provide energy at efficiencies of between 50\% to $80 \%$. The use of low-grade feedstocks combined with high conversion efficiencies makes these systems economically competitive with cheap coal-based plants and energetically competitive with natural gas-based plants. Studies are continuing in the use of such technologies for the cost effective treatment of MSW considers that "gasification can become a strong competitor to anaerobic digestion, composting and incineration for biomass waste treatment." This is based on the use of BIG/STIG technology with the system gasification using Atmospheric Circulating Fluidized Bed technology.

\subsubsection{Catalytic Liquefaction}

This technology has the potential to produce higher quality products of greater energy density. These products should also require less processing to produce marketable products. Catalytic liquefaction is a low temperature, high pressure thermochemical conversion process carried out in the liquid phase. It requires either a catalyst or a high hydrogen partial pressure. Technical problems have so far limited the opportunities of this technology.

\subsection{Biochemical Processes}

The use of micro-organisms for the production of ethanol is an ancient art. However, in more recent times such organisms have become regarded as biochemical "factories" for the treatment and conversion of most forms of human generated organic waste. Microbial engineering has encouraged the use of fermentation technologies (aerobic and anaerobic) for use in the production of energy (biogas) and fertiliser, and for the use in the removal of unwanted products from water and waste streams [5].

a) Anaerobic Fermentation.

b) Methane Production in Landfills.

c) Ethanol Fermentation. 


\subsubsection{Anaerobic Fermentation}

Anaerobic digestion is the microbial digestion of feedstock releasing heat, methane, hydrogen sulphide, carbon dioxide and under specific conditions hydrogen gas. This process takes place over several days in large tanks where the ideal conditions are maintained. After the process the remaining solid digestate is suitable for use as fertiliser and the gases released are collectively referred to as biogas. This gas can be used as a fuel in a CHP scheme once the gas has been cleaned to remove acidic compounds by condensation.

Anaerobic reactors are generally used for the production of methane rich biogas from manure (human and animal) and crop residues. They utilise mixed methanogenic bacterial cultures which are characterised by defined optimal temperature ranges for growth. These mixed cultures allow digesters to be operated over a wide temperature range i.e. above $0^{\circ} \mathrm{C}$ up to $60^{\circ} \mathrm{C}$.

When functioning well, the bacteria convert about $90 \%$ of the feedstock energy content into biogas (containing about 55\% methane), which is a readily useable energy source for cooking and lighting. The sludge produced after the manure has passed through the digester is non-toxic and odourless. Also, it has lost relatively little of its nitrogen or other nutrients during the digestion process thus, making a good fertiliser. In fact, compared to cattle manure left to dry in the field the digester sludge has a higher nitrogen content; many of the nitrogen compounds in fresh manure become volatised whilst drying in the sun.

The advantage of anaerobic digestion is that it naturally occurs to organic material and would release methane, a potent greenhouse gas, into the atmosphere. Capturing and combusting the methane makes use of the energy in the gas and produces carbon dioxide which is a less potent greenhouse gas than methane and offsets fossil fuel energy production.

The disadvantages of anaerobic digestion are that the microbes required pose a health threat to people and livestock. The microbes are sensitive to changes in the feedstock, especially the presence of anti-microbial compounds, and changes in the reactor conditions: they require constant circulation of the reactor fluid, and a constant operating temperature and $\mathrm{pH}$.

Anaerobic digesters of various types were widely distributed throughout India and China. Extension programmes promote biogas plants as ideal candidates for rural village use due to their energy and fertiliser production potential along with their improved health benefits. Health benefits primarily arise from the cleaner combustion products of biogas as opposed to other biomass or fossil fuels which may be used in the domestic environment. Reliability problems have arisen from a number of problems i.e. construction defects, the mixed nature of the bacterial population, the digesters requirements for water \& maintenance of optimum nitrogen ratio of the medium. Another problem is the digester's demand for dung, which may have alternative uses [6].

\subsubsection{Methane Production in Landfills.}

Methane is a powerful greenhouse gas, with substantial amounts being derived from unutilized methane production from landfill sites. Its recovery therefore, not only results in the stabilisation of the landfill site, allowing faster reuse of the land, but also serves to lessen the impact of biospheric methane emissions on global warming. Anaerobic digestion in landfills is brought about by the microbial decomposition of the organic matter in refuse. The levels of organic matter produced per capita vary considerably from developed to developing countries e.g. the percentage of Municipal Solid Waste (MSW) which is putrescible in Sierra Leone is about $90 \%$ compared to about $60 \%$ for US MSW. Commercial production of land-gas can also aid with the leaching problems now increasingly associated with landfill sites. Local communities neighbouring land fill sites are becoming more aware of the potential for heavy metals and nutrients to leach into aquifers. Landfill processing reduces the volume of sludge to be disposed of, and the nutrient content, thus facilitating proper disposal.

\subsubsection{Fermentation}

Ethanol is mainly used as a substitute for imported oil in order to reduce their dependence on imported energy supplies. The substantial gains made in fermentation technologies now make the production of ethanol for use as a petroleum substitute and fuel enhancer, both economically competitive (given certain assumptions) and environmentally beneficial. The most commonly used feedstock in developing countries is sugarcane, due to its high productivity when supplied with sufficient water. Where water availability is limited, sweet sorghum or cassava may become the preferred feedstocks. Other advantages of sugarcane feedstock include the high residue energy potential and modern management practices which make sustainable and environmentally benign production possible whilst at the same time allowing continued production of sugar. Other feedstocks include saccharide-rich sugarbeet, and carbohydrate rich potatoes, wheat and maize.

Recent advances in the use of cellulosic feedstock, may allow the competitive production of alcohol from woody agricultural residues and trees to become economically competitive in the medium term. 


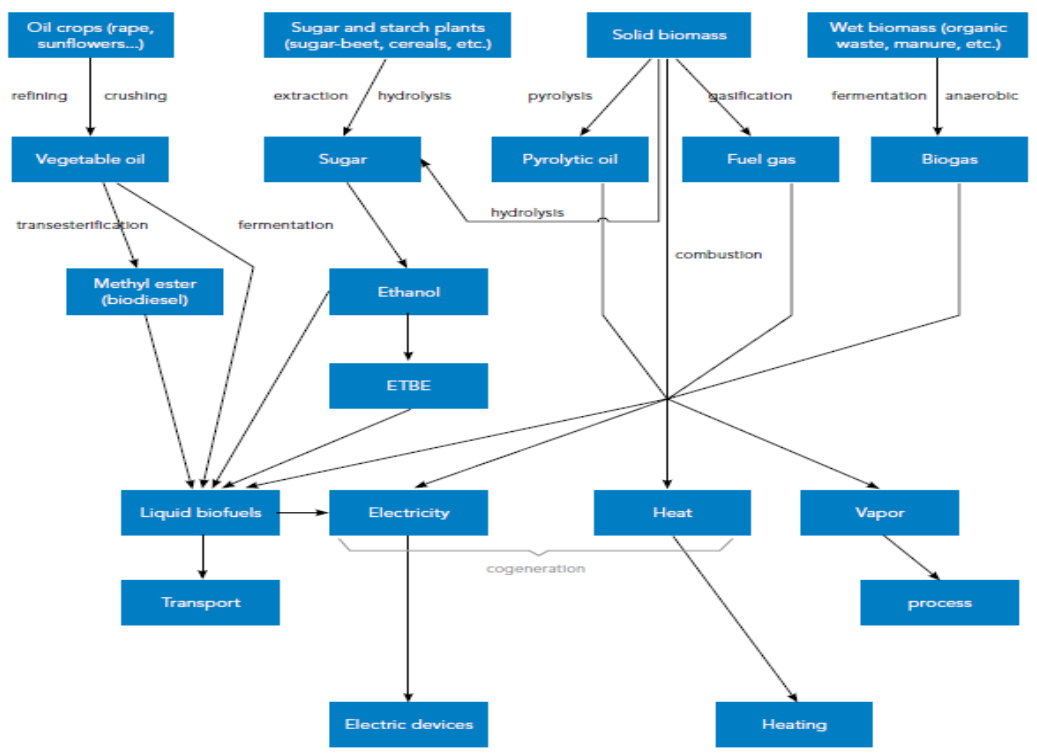

Fig -3: Biomass Energy Conversion Overview Source: Renewable Energy World, 2006.

\section{Advanced Technologies}

The research programs funded by the public and private sectors to develop renewable energy technologies since the First Oil Shock have led to numerous scientific and engineering advances for basically all renewable energy resources. Some of the advanced biomass-related technologies are listed here. Many of them have already been or will be commercialized.

* Advanced plantation designs for the managed multicropping of virgin biomass species in integrated biomass production-conversion systems.

* Advanced biorefinery system designs for the sustained production of multiple product slates.

* High rate anaerobic treatment processes for greater destruction of pathogens and biosolids in wastewaters at higher biogas yields and production rates.

* Close-coupled biomass gasification-combustion systems for the production of hot water and steam for commercial buildings and schools.

* Advanced biomass gasification processes for the high-efficiency production of medium-energycontent fuel gas and power.

* Zero-emissions waste biomass combustion systems for combined disposal-energy recovery and recycling.

* Catalysts for thermochemical gasification of biomass feedstocks to product gases for conversion to preselected chemicals in high yields.

* Short-residence-time pyrolysis processes for the production of chemicals and liquid fuels from biomass.

* Genetically engineered microorganisms capable of simultaneously converting all pentose and hexose sugars from cellulosic biomass to fermentation ethanol.

\section{Integrated Biomass Production-Conversion Systems (Ibpcs)}

The energy potential of waste biomass, although of significant importance for combined waste disposal, energy-recovery applications, is relatively small compared to the role that virgin biomass has as an energy resource. The key to the large-scale production of energy, fuels, and commodity chemicals from biomass is to grow suitable virgin biomass species in an integrated biomass-production conversion system (IBPCS) at costs that enable the overall system to be operated at a profit. Multiple feedstocks, including combined biomass fossil feedstocks and waste biomass, may be employed [7].

The proper design of an IBPCS requires the coordination of numerous operations such as biomass planting, growth management, harvesting, storage, retrieval, transport to conversion plants, drying, conversion to products, emissions control, product separation, recycling, wastewater and waste solids treatment and disposal, maintenance, \& transmission or transport of salable products to market.(Fig. 4). 


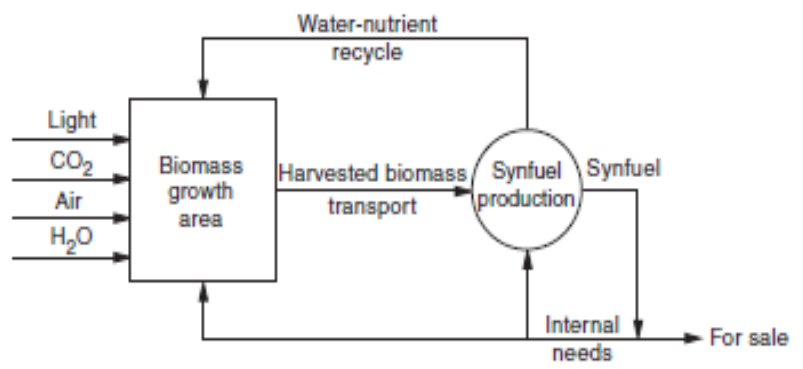

Fig -4: Idealized biomass growth and manufacturing system. From Klass (1998).

The design details of the IBPCS depend on the feedstocks involved and the type, size, number, and location of biomass growth and processing areas needed. It is evident that a multitude or parameters are involved. In the idealized case, the conversion plants are located in or near the biomass growth areas to minimize the cost of transporting biomass to the plants, all the nonfuel effluents of which are recycled to the growth areas. If this kind of plantation can be implemented in the field, it would be equivalent to an isolated system with inputs of solar radiation, air, $\mathrm{CO}_{2}$, and minimal water; the outputs consist of the product slate. The nutrients are kept within the ideal system so that addition of external fertilizers and chemicals is not necessary. Also, the environmental controls and waste disposal problems are minimized.

The growth areas required to supply quad blocks of energy and fuels would be very large when compared with conventional agricultural practice, but that 10,000- boe/day systems are not quite so large when compared with traditional, sustainable wood harvesting operations in the forest products industry. The analysis suggests that smaller, localized IBPCSs in or near market areas will be preferred because of logistics and product freight costs, and multiple feedstocks and products will have advantages for certain multiproduct slates. Synthesis gas from biomass gasification used as cofeedstock in an existing natural gas-to-methanol plant can utilize the excess hydrogen produced on steam reforming natural gas [8].

Sustainable virgin biomass production at optimum economic yields is a primary factor in the successful operation of IBPCSs. Most of the IBPCSs that have been proposed are site specific - that is, they are designed for one or more biomass species, in the case of a multicropping system, for specific regions. Some of the large, commercial forestry operations for tree growth, harvesting, and transport to the mills can be considered to be analogous in many respects to the biomass production phase of managed IBPCSs [16].

\section{Conclusions}

The technologies include a large variety of thermal and thermochemical processes for converting biomass by combustion, gasification, and liquefaction, and the microbial conversion of biomass to obtain gaseous and liquid fuels by fermentative methods. Examples of the former are wood-fueled power plants in which wood and wood wastes are combusted for the production of steam, which is passed through a steam turbine to generate electricity. Examples of microbial conversion are the anaerobic digestion of biosolids to yield a relatively high-methane-content biogas of medium energy value and the alcoholic fermentation of corn to obtain fuel ethanol for use as an oxygenate and an octane-enhancing additive in motor gasolines.

Many of the processes are suitable for either direct conversion of biomass or conversion of intermediates. The processes are sufficiently variable so that liquid and gaseous fuels can be produced that are identical to those obtained from fossil feedstocks, or are not identical but are suitable as fossil fuel substitutes. It is important to emphasize that virtually all of the fuels and commodity chemicals manufactured from fossil fuels can be manufactured from biomass feedstocks.

Indeed, several of the processes used in a petroleum refinery for the manufacture of refined products and petrochemicals can be utilized in a biorefinery with biomass feedstocks. Note also that selected biomass feedstocks are utilized for conversion to many specialty chemicals, pharmaceuticals, natural polymers, and other higher value products.

The historical development of IBPCSs shows that large-scale biomass energy plantations must be planned extremely carefully and installed in a logical scale-up sequence. Otherwise, design errors and operating problems can result in immense losses and can be difficult and costly to correct after construction of the system is completed and operations have begun. It is also evident that even if the system is properly designed, its integrated operation can have a relatively long lag phase, particularly for tree plantations, before returns on investment are realized. The financial arrangements are obviously critical and must take these factors into consideration. 


\section{References}

[1]. “Bioenergy '96, Proceedings of the Seventh National Bioenergy Conference, '”Vols. I-II. (1996).

[2]. Bisio, A., Boots, S., and Siegel, P. (eds.). (1997). "The Wiley Encyclopedia of Energy and the Environment, Vols. I-II." John Wiley \& Sons, New York.

[3]. Bridgwater, A. V., and Grassi, G. (eds.). (1991). “Biomass Pyrolysis Liquids Upgrading and Utilization.” Elsevier Science, Essex, United Kingdom.

[4]. Chartier, P., Beenackers, A. A. C. M., and Grassi, G. (eds.). (1995). “'Biomass for Energy, Environment, Agriculture, and Industry, Vols. I-III (and previous and subsequent biennial books).' Elsevier Science, Oxford, United Kingdom.

[5]. Cross, B. (ed.). (1995). “The World Directory of Renewable Energy Suppliers and Services 1995." James \& James Science, London, United Kingdom.

[6]. "First Biomass Conference of the Americas: Energy, Environment, Agriculture, and Industry," Vols. I-III (1993, 1942). NREL/CP- 200-5768, DE93010050 (and subsequent biennial books). National Renewable Energy Laboratory, Golden, CO.

[7]. Klass D. L. Biomass for Renewable Energy and Fuels. Encyclopedia of Energy, Elsevier, Inc. $r 2004$.

[8]. Klass, D. L. (1998). "Biomass for Renewable Energy, Fuels, and Chemicals.”' Academic Press, San Diego, CA.

[9]. Klass, D. L., and Emert, G. H. (eds.). (1981). "Fuels from Biomass and Wastes. Ann Arbor Science." The Butterworth Group, Ann Arbor, MI.

[10]. Directory of U.S. "Renewable Energy Technology Vendors: Biomass, Photovoltaics, Solar Thermal, Wind.', (1990). Biomass Energy Research Association, Washington, DC.

[11]. Hogan, E., Robert, J., Grassi, G., and Bridgwater, A. V. (eds.). (1992). “Biomass Thermal Processing. Proceedings of the First Canada/European Community Contractors Meeting." CPL Press, Berkshire, United Kingdom.

[12]. Bridgwater AV. - Thermal biomass conversion and utilization - Biomass information system published by the office for official publications of the European Community - EUR 16863 EN- 1996.

[13]. Lede J., Diebold J.P., Peacocke GVC, Piskorz J. - The nature and properties of intermediate and unvapourized biomass pyrolysis materials in Developments in thermochemical biomass conversion - Banff- Canada - Edited by Black academic \& professional 1997.

[14]. Prins W., Wagenaar BM. - Review of rotating come technology for flash pyrolysis of biomass in Biomass Gasification and pyrolysis - State of the art and futures prospects -CPL press 1997.

[15]. Adjaye J.D., Bakhshi N.N. - Characteristics of ENSYN FAST pyrolysis oils in Bio-Oil production and utilisation in Proceeding of the 2nd EU Canada Worshop thermal biomass processing - CPL press - 1996.

[16]. Gust S. Combustion of pyrolysis liquids Biomass gasification and pyrolysis State of the art and futures prospects $C P L$ press 1997 . 